\title{
PSYCHOSOCIAL EFFECTS ON WOMEN PRESENTING WITH HIRSUTISM
}

\author{
Dr. Riaz Gul ${ }^{1}$, Dr. Mustafa Alam², Dr. Mukhtar-Ul- Haq ${ }^{3}$. \\ 1- Kabir institute of public health, Peshawar. \\ 2- Kabir institute of public health ,Peshawar(scholar) \\ 3-Psychiatry ward, lady reading hospital Peshawar.
}

\begin{abstract}
Objectives

To determine different psychosocial effects in different classes of hirsute ladies and to assess the level of depression in them due to Hirsutism.

Methodology

Cross sectional study conducted for duration of three months from Jan 10, 2013 to April 30, 2013.at a private clinic of laser therapy on 115 patients who visited the clinic for treatment with some degree of Hirsutism.non probability convenient sampling technique was used for cases selection. A structured questionnaire was used for data collection which was designed with consultation of psychiatrist from lady reading hospital Peshawar. All patients of different classes were included in the study. Patients with other dermatological disorders were excluded from the study. A pilot study was conducted on $10 \%$ of sample size. . Prior consent was taken from all respondent after explaining the purpose of the study.

The data was collected, tabulated, analyzed, and interpreted by SPSS Version 16 and the results were presented in form of tables and graphs.
\end{abstract}

\section{Results}

We found in our study that majority of patients of Hirsutism who visited for treatment were of young age i.e.from15 to 25 years (82.5\%) and most of them presented with some abnormal psychosocial effects.(81.4\%).

Abnormal psychosocial effects were found more in patients who came from urban areas(84.7\%) as compared to those who came from rural areas(77.4\%), more in un married females (86.3\%) as compared to married (73\%), more common in employed class (91.2\%) as compared to un employed. When behavior of the colleagues with them due to their Hirsutism was asked it was found that most of them (83\%) responded that the attitude of their colleges with them is abnormal due to their Hirsutism due to which majority of them (86.8\%) hide their disease from others.

to assess the level of anxiety/ depression in patients due to their disease a standard scale was used, and was found that $73(83.2 \%)$ were having moderate to severe anxiety (score 11-21) while 16(16.8\%) were having border line anxiety (score 8-10).

\section{Conclusion}

Patients with Hirsutism usually present with some degree of psychosocial effect which lead them to anxiety and depression. The psychosocial effects in women with Hirsutism were found more common in young age, working class ladies, un married and females residing in urban areas.

\section{Recommendations}

Health education regarding the disease, social and moral support to the patients, treatment facilities at all district levels especially laser therapy should be provided.

Key words:

Hirsutism, psychosocial effects, anxiety, depression, 


\section{INTRODUCTION}

Hirsutism is defined as the abundant growth of thick dark hair in areas where hair growth in women usually is absent or minimum. Such male-pattern growth of hairs usually occur in locations stimulated by androgens, like face, chest, and areolae.in hirsuitism women have excess facial and body hair that is dark and coarse. The abnormal hair growth usually occurs on the body where men typically grow hair, on the, face, chest, and back. ${ }^{1}$

Presence of some body and facial hair is normal, and the amount varies among women .In around half of women with the male hormones level is high leading to hirsuitism. Majority cases of Hirsutism are not severe and have no obvious cause. Sometimes there is a more serious underlying condition, such as Cushing's syndrome. ${ }^{2}$

Hirsuitism affects $5-15 \%$ of women; around $40 \%$ of the females have a degree of unwanted facial hair. Different studies regarding psychological effects of facial hirsutism has indicated a reduced quality of life in women with Hirsutism. About $27 \%$ of hirsute patients have been found to have psychiatric disturbances out of which $30 \%$ have clinical depression and $75 \%$ reported with clinical anxiety. ${ }^{3}$

Hirsutism is caused by abnormally high androgen levels or by hair follicles that are more sensitive to normal androgen levels. Therefore, it is often observed in patients who have endocrine disorder leading to hyperandrogenism caused by disorder of ovaries or adrenal glands. ${ }^{4}$ increase level of androgens lead to increase size of hair follicle, increase in the diameter of fiber and duration of growth phase of follicle. Excess androgen apart from causing change in hair quality and volume leads to oilier skin. Androgens also alter the distribution of hair in women, leading to excess hair growth occurs in androgen-sensitive regions, but there occurs loss of hairs on the scalp. ${ }^{5}$

A psychosocial disorder is a mental illness which is caused or influenced by life experiences, as well as maladjusted cognitive and behavioral processes. The psychological and social factors that influence mental health are called as psychosocial.

Peer pressure, cultural and religious background, socioeconomic status, parental support, and interpersonal relationships all are the factors that help to make personality and affects psychological makeup. Those peoples, who have psychosocial disorders, face difficulty functioning in social situations and may communication problems. ${ }^{6}$

Hirsutism badly affects self-esteem and body image. Women with hirsuitism report feeling abnormal, unfeminine, and embarrassed. ${ }^{7}$ most of these women avoid physical closeness with others to conceal it. The common abnormal behavior reported with hirsuitism are touching face, using mirror to see their faces throughout the day, covering their faces when talking to others, and avoiding close contact with others. Studies have shown that as most of the women are not able to deal with their hirsuitism properly so they experience depression and anxiety more than caused by any major illness. ${ }^{7-8}$

The purpose of this study is to assess the level of psychosocial effect on female of different classes who are coming to private clinic for treatment of their hirsuitism. For this purpose women with hirsutism from different classes were included in the study sample. 


\section{METHODS AND MATERIAL}

It was a cross sectional study conducted at private clinic on females who attended the clinic with some degree of hirsutism from $10^{\text {th }}$ January, 2013 to $30^{\text {th }}$ April 2013.

The psychosocial effect due to hirsutism on these females belonging to different classes were assessed using a well structured questionnaire the questionnaire was printed both in English and Urdu language for patient convenience. The level of anxiety / depression in these women was assessed using standard criteria. Non probability sampling technique was used .115 ladies of 15 to 60 years ages and different classes (married/un married, working /non working, urban/rural) were included in the study who were having some degree of Hirsutism.

Female with Hirsutism and other dermatological disorders were excluded from the study. A pilot study was conducted on $10 \%$ of sample size to check the feasibility and applicability of questionnaire. Two female staff members were trained on questionnaire that filled the questionnaire in person. Prior consent was taken from all respondent after explaining the purpose of the study.

The data was collected, tabulated, analyzed, and interpreted by SPSS Version 16 and the results were presented in form of tables and graphs.

\section{RESULTS}

Out of total 115 patients visited with problem of Hirsutism during the study time majority of the patients were in the age group of 15 to 25 years $(57.4 \%)$ while the frequency of patients with other age groups were, age 26-35 years are $39(33.9 \%)$ and age $36-45$ years are $10(8.7 \%)$ shown in table and figure 1.

Different psychosocial effects were found to be present in 85 patients out of total $115(82.5 \%)$ and 18 patients were found to be with no psychosocial effects $(17.5 \%)$ as shown in table 2 .

Results shown in table 3 in age group of $15-25$ is $81.4 \%$ in abnormal scale and $18.6 \%$ in normal, in age $26-35$ is $89.2 \%$ in abnormal scale and $10.8 \%$ in normal, and in age $36-45$ is $57.1 \%$ in abnormal and $42.9 \%$ in normal. It is found that in urban $84.7 \%$ were in abnormal and $15.3 \%$ in normal. While in rural area $77.4 \%$ were abnormal and $23.6 \%$ normal. As shown in table 4.

In married patients $73.3 \%$ were abnormal and $26.7 \%$. While in unmarried patients $86.3 \%$ in abnormal scale and $13.7 \%$ in abnormal scale as shown in table 5.

Table 6 shows that in employed patients $91.2 \%$ found abnormal while $8.8 \%$ was normal. However, in unemployed patient we find $80.3 \%$ find abnormal and $19 \%$ normal.

Table 7 shows the behavior of colleagues in working place found $83 \%$ were abnormal and normal $17 \%$. While the behavior of colleagues in working place having different behavior found $100 \%$ were abnormal.

It was found in the study that most females hide their hirsutism from other people that created a great psychosocial effect upon their self esteem and that let them to lose their interest in their appearance. We have found that the patients who hide their disease from others were $86.8 \%$ in abnormal scale, while in normal $13.2 \%$. The results show that the patients lost interest in their appearance $73.3 \%$ in abnormal and $26.7 \%$ as shown in table 8 .

Out of 85 patients ( $82.5 \%$ ) with some level of psychosocial problem due to hirsutism, a well designed standardized level was used to assess their level of anxiety and depression with consultation of the psychiatrist from psychiatry department of lady reading hospital Peshawar 
and it was found that $16(16.8 \%)$ number of patients obtained a score of $8-10$ and were labeled as having border line anxiety and depression level while $79(83.2 \%)$ number of patients obtain the score of $11-21$ which according to the scale were labeled as having moderate to severe degree of anxiety and depression the same results are shown in figure 9.

Table-1. Age wise distribution of patients attended the clinic with hirsutism in $10^{\text {th }}$ January to $30^{\text {th }}$ April 2013 out of total patients 115.

\begin{tabular}{|l|l|l|}
\hline Age & Frequency & Percent \\
\hline $15-25$ & 66 & 57.4 \\
$26-35$ & 39 & 33.9 \\
$36-45$ & 10 & 8.7 \\
Total & 115 & 100.0 \\
\hline
\end{tabular}

Table-2. Percentage of patients presenting with psychosocial effects due to hirsutism in the study population attended the clinic with hirsutism in $10^{\text {th }}$ January to $30^{\text {th }}$ April 2013.

\begin{tabular}{|l|l|l|}
\hline Psychosocial effects & Frequency & Percent \\
\hline Abnormal & 85 & 82.5 \\
Normal & 18 & 17.5 \\
Total & 103 & 100.0 \\
\hline
\end{tabular}

Table-3. Age wise distribution of patient with psychosocial effects due to Hirsutism in study population attended the clinic from $10^{\text {th }}$ January to April $30^{\text {th }} 2013$.

\begin{tabular}{|l|l|l|}
\hline \multirow{2}{*}{ Age } & \multicolumn{2}{|c|}{ Psychosocial effects } \\
\cline { 2 - 3 } & Abnormal & Normal \\
\hline $15-25$ & 48 & 11 \\
& $81.4 \%$ & $18.6 \%$ \\
\hline $26-35$ & 33 & 4 \\
& $89.2 \%$ & $10.8 \%$ \\
\hline $36-45$ & 4 & 3 \\
& $57.1 \%$ & $42.9 \%$ \\
\hline
\end{tabular}


Table-4. Geographical distribution of patient having psychosocial effects due to hirsutism in study population attended the clinic from $10^{\text {th }}$ January to April $30^{\text {th }} 2013$.

\begin{tabular}{|c|c|c|}
\hline \multirow{2}{*}{ Area } & \multicolumn{2}{|c|}{ Psychosocial effects } \\
\cline { 2 - 3 } & Abnormal & Normal \\
\hline \multirow{2}{*}{ Urban } & 61 & 11 \\
& $84.7 \%$ & $15.3 \%$ \\
\hline \multirow{2}{*}{ Rural } & 24 & 7 \\
& $77.4 \%$ & $22.6 \%$ \\
\hline
\end{tabular}

Table-5. Marital status wise distribution of patient with psychosocial effects due to hirsutism in study population attended the clinic from $10^{\text {th }}$ January to April $30^{\text {th }} 2013$.

\begin{tabular}{|c|c|c|}
\hline \multirow{2}{*}{ Marital status } & \multicolumn{2}{|c|}{ psychosocial effects } \\
\cline { 2 - 3 } & Abnormal & Normal \\
\hline \multirow{2}{*}{ Married } & 22 & 8 \\
& $73.3 \%$ & $26.7 \%$ \\
\hline \multirow{2}{*}{ Unmarried } & 63 & 10 \\
& $86.3 \%$ & $13.7 \%$ \\
\hline
\end{tabular}

Table-6. Employed and unemployed wise distribution of patient with psychosocial effects due to hirsutism in study population attended the clinic from $10^{\text {th }}$ January to April $30^{\text {th }}$ 2013.

\begin{tabular}{|c|c|c|}
\hline \multirow{2}{*}{$\begin{array}{c}\text { Employed or } \\
\text { unemployed }\end{array}$} & \multicolumn{2}{|c|}{ psychosocial effects } \\
\cline { 2 - 3 } & Abnormal & Normal \\
\hline Employed & 31 & 3 \\
& $91.2 \%$ & $8.8 \%$ \\
\hline Unemployed & 53 & 13 \\
& $80.3 \%$ & $19.7 \%$ \\
\hline
\end{tabular}


Table-7. Behavior of colleagues in working place with patients having psychosocial effects due to hirsutism in study population attended the clinic from $10^{\text {th }}$ January to April $30^{\text {th }} 2013$.

\begin{tabular}{|c|c|c|}
\hline \multirow{2}{*}{ Behavior of your colleague with you } & \multicolumn{2}{|c|}{ psychosocial effects } \\
\cline { 2 - 3 } & Abnormal & Normal \\
\hline \multirow{2}{*}{ Normal } & 39 & 8 \\
& $83.0 \%$ & $17.0 \%$ \\
\hline \multirow{2}{*}{ Different } & 11 & 0 \\
& $100.0 \%$ & $.0 \%$ \\
\hline
\end{tabular}

Table 8. loss of interest in appearance of respondents due to Hirsutism with psychological effects.

\begin{tabular}{|c|c|c|}
\hline \multirow{2}{*}{ Lost interest in appearance } & \multicolumn{2}{|c|}{ psychosocial effects } \\
\cline { 2 - 3 } & Abnormal & Normal \\
\hline \multirow{2}{*}{ Yes } & 44 & 16 \\
& $73.3 \%$ & $26.7 \%$ \\
\hline No & 41 & 2 \\
& $95.3 \%$ & $4.7 \%$ \\
\hline
\end{tabular}

Table-9. Different level of psychosocial effects in patients with hirsutism in study population using a standard scale.

\begin{tabular}{|l|c|c|}
\hline Level of psychosocial effects & Frequency & Percent \\
\hline & 16 & 16.8 \\
border line Abnormal Total & 79 & 83.2 \\
& 95 & 100.0 \\
\hline
\end{tabular}

\section{DISCUSSION}

This survey was carried out to identify the psychosocial effects on women presenting with Hirsutism and also to assess the level of anxiety / depression in such patients. 
As for as the age is concern high number of hirsute women visited the clinic from age $15-25$ years $(57.4 \%)$, age $26-35$ years ( $33.9 \%$ ) and age $36-45$ years $(8.7 \%)$.It shows that the younger age group is more concerned regarding their disease.

It's obvious from the results that high percentage of women with Hirsutism are having some degree of psychosocial effects (82\%).As the females are more conscious about their look and that could be the probable reason that why high percentage of females having Hirsutism also present with some psychosocial effects.

From our study it is also obvious that majority of the patients with psychosocial effects due to hirsutism who came to our clinic were from the age 15 to 25 years (59\%). The figure doesn't shows any relation regarding the cause of hirsutism with age but it's a clear indication that the female in this age are more concerned about their look and aesthetic sense.

We found in our study that the among 115 hirsute women who attended the clinic for laser therapy 72 were from urban area and 31 were from rural area it is more than two times from urban area as compare to rural .The reasons of high frequency of urban residing patients could be due to the fact that the study was conducted in an urban sitting. Awareness among urban residing patients regarding their sense of aesthetic, and their affordability of the treatment. But the frequency of psychosocial effects on patients from both urban and rural sittings were found to be non significant.

The comparison shows a little difference in psychosocial effects due to hirsutism among married and unmarried women's, $73.3 \%$ abnormality seen in married and $86.3 \%$ abnormality seen in unmarried women. It shows that the marital status has no impact on psychosocial effects.

While in our study we found that the psychosocial effect on women of different classes has no significance with regard to their life style, behavior from their colleagues.

The behavior of colleagues in working place in relation to psychosocial effects with patients with hirsutism the results shows that in majority of cases it was found normal while in few cases $(11 \%)$ it was found that the colleagues were behaving in a different way than normal with patients with hirsutism and that was found to be the main reason which let them into anxiety and depression.

The total abnormality regarding patients feeling about her having this disease is $82(82.8 \%)$, Where it is $51(81 \%)$ normal feelings and abnormal feelings are $31(86.1 \%)$. The analysis reveals that the women having hirsutism hide this disease from other people. The study show that 91 women replied that yes they hide this disease from other people while only 12 replied that they don't hide this disease from people. it is highly significant .the reason behind such a significant level of anxiety in women and in general population is the lack of awareness regarding the disease, in our culture as compare to the developed countries hirsutism is considered as social stigma and that could be the probable reason that why such a high percentage of patients hide their hirsutism from other people, despite of the fact that hirsutism is a disease as like many other diseases having some medical causes rather than some social causes. The same results were shown by a study conducted by Escobar-Morreale, H.F. Ann N Y Acad in year 2010 regarding the psychosocial effects and quality of life among women .with hirsutism. 
It is also significant that the hirsute women has low interest in their appearance, study show 60 $\%$ replied yes they have low interest in their appearance and $43 \%$ replied that they still have interest in their appearance. The reason behind their lost of interest could be the lack of awareness regarding the management procedure, their high cost of treatment which cannot be affordable to most of the patients and the lack of such treatment facilities in the government sector hospitals which is within the limit of most of the patients. All these factors led to the sense of frustration in such patients that created lost of interest in their appearance as well as in their happy life. In this regard a study was conducted by Moghetti, P,;Tosi, F and Tosti, A, J Clin Endocrinol Metab in year 2000 who found in their studies that women with hirsutism with psychosocial disorders frequently have difficulty functioning in social situations and may have problems efficiently communicating with others.

While assessing the level and frequency of anxiety and depression in women with hirsutism it was found in our study that majority of our respondents were presented with some level of anxiety and depression, which is high as compare to the developed countries and reason could be lack of awareness regarding the management, lack of facilities, and their affordability.

\section{CONCLUSION}

On the basis of our discussion we conclude that Majority of the patients with hirsutism were found to be having some degree of psychosocial effect upon their personalities due to their disease. The psychosocial effects in women with hirsutism were found more common in young age, working class ladies, unmarried and females residing in urban areas.

\section{RECOMMENDATIONS}

On the basis of our conclusion following recommendations are made for the general public and specifically for the patients with hirsutism.

Mass health education should be provided to the public regarding the disease and its management.

The government should provide the treatment facilities at all district level so that all the patients have an access to avail the facilities.

Social and moral support by Health and social workers.

The medical staff who are concerned with those patients may assess the psychosocial effects and to treat them accordingly or to refer them to clinical psychologist, psychotherapist or psychiatrist if needed. 


\section{REFERENCES}

1. Mofid A, Seyyed Alinaghi SA, Zandieh S, Yazdani T. Hirsutism. Int J ClinPract. Mar 2008;62(3):43343. [Medline].

2. Abdel Fattah NS, Darwish YW. Is there a role for insulin resistance in nonobese patients with idiopathic hirsutism?.Br J Dermatol. May 2009;160(5):1011-5. [Medline].

3. Escobar-Morreale HF. Diagnosis and management of hirsutism. Ann N Y Acad Sci. Sep 2010;1205:166-74. [Medline]

4. Moghetti P, Toscano V. Treatment of hirsutism and acne in hyperandrogenism. Best Pract Res ClinEndocrinolMetab. Jun 2006;20(2):221-34. [Medline].

5. Moghetti P, Toscano V. Treatment of hirsutism and acne in hyperandrogenism. Best Pract Res ClinEndocrinolMetab. Jun 2006;20(2):221-34. [Medline].

6. Moghetti P, Tosi F, Tosti A, et al. Comparison of spironolactone, flutamide, and finasteride efficacy in the treatment of hirsutism: a randomized, double blind, placebo-controlled trial. J ClinEndocrinolMetab. Jan 2000;85(1):89-94. [Medline].

7. Pasch LA, Lamb J, Shelly $W$, et al. Factors associated with risk for depression among women with polycystic ovary syndrome. FertilSteril. 2008;90(suppl):S178.

8. Mofid, A.; Alinaghi, S.; Zandieh, S and Yazdani, T,; Hirsutism. Int J ClinPract, 2008; 62,3, 433-443.

9. AbdelFattah,; N.S and Darwish, Y.W.Br J Dermatol, 2009, 160, 5, 1011-1055.

10. Escobar-Morreale, H.F. Ann N Y Acad Sci, 2010, 1205, 166-176.

11. Moghetti, P.;Toscano, V. ClinEndocrinolMetab, 2006,20,2, 221-234.

12. Moghetti, P.; Toscano, V.Best Pract Res ClinEndocrinolMetab2006, 20,

13. Moghetti, P,;Tosi, F and Tosti, A, J ClinEndocrinolMetab, 2000, 85,1, 89-94.

14. Pasch, L.A,; Lamb,; J and Shelly, W. FertilSteril2008, 90,(suppl), S178.

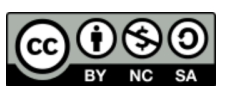

LICENSE: JGMDS publishes its articles under a Creative Commons Attribution Non-Commercial Share-Alike license (CC-BY-NC-SA 4.0). COPYRIGHTS: Authors retain the rights without any restrictions to freely download, print, share and disseminate the article for any lawful purpose. It includes scholarly networks such as Research Gate, Google Scholar, LinkedIn, Academia.edu, Twitter, and other academic or professional networking sites. 